\title{
KAJIAN DESORPSI ZAT WARNA INDIGOSOL BLUE DARI ADSORBEN HUMIN HASIL ISOLASI TANAH GAMBUT RIAU, SUMATERA
}

\author{
Girda Wahyu Ekowati ${ }^{1}$, Maya Rahmayanti ${ }^{1}$ \\ ${ }^{1}$ Program Studi Kimia, Fakultas Sains dan Teknologi Universitas Islam Negeri Sunan Kalijaga, \\ Jl.Laksda Adisucipto, Yogyakarta 55281 Indonesia \\ Wahyugirda@gmail.com
}

\begin{tabular}{|l|}
\hline $\begin{array}{l}\text { Artikel Info } \\
\text { Diterima }\end{array}$ \\
15.09.2019 \\
Disetujui \\
publikasi \\
tanggal \\
31.10.2019 \\
Kata kunci : \\
desorbsi, \\
indigosol blue, \\
zat warna
\end{tabular}

\section{ABSTRACT}

In this study, the desorption of indigosol blue dyes on humin adsorbent from the isolation of peat soils in Riau, Sumatera has been succesfully done. Desorption was carried out by using $\mathrm{HCl}$ as desorption agents with varied concentrations of 0,$5 ; 1,0 ; 1,5 ; 2,0 \mathrm{M}$ and without using desorption agents. After the desorption process, there was a shift in the wavelenght at adsorption peak of the functional group of humin adsorbents. This indicated that the active group of indigosol blue dyes was absorbed at the time of adsorption. The spectra FT-IR after desorption showed that there was a shift in the wavelenght which indicated that the active group of indigosol blue dyes had been distorted. The optimum concentration of indigosol blue dye desorption on humin adsorben at 1,5 $\mathrm{M}$.

\section{PENDAHULUAN}

Zat warna sintetik yang sering digunakan pada industri tekstil salah satunya adalah zat warna indigosol blue. Zat warna indigosol blue sering digunakan pada proses pewarnaan dalam industri tekstil karena harganya yang ekonomis dan cara memperolehnya relatif mudah. Zat warna ini memiliki struktur molekul dua cincin benzena yang sangat stabil, sehingga keberadaannya dalam lingkungan perairan tidak mudah diuraikan secara biologis dan menambah kesulitan dalam pengolahannya (Suparno, 2010). Penanganan zat warna hasil industri tekstil tersebut dapat dilakukan dengan menggunakan metode yang efektif dan efisien, salah satunya menggunakan teknik adsorpsi. 
Teknik adsorpsi pada pengolahan limbah semakin banyak diaplikasikan karena efisiensinya dalam pemisahan polutan yang sulit untuk dipisahkan secara biologis(Atkins, 1997).

Beberapa jenis adsorben yang dapat digunakan untuk mengolah limbah zat warna antara lain zeolit (Pohan dkk, 2018); asam humat (Larasati, 2018) dan batu apung (Heland, 2018). Selain itu, adsorben lain yang dapat digunakan adalah humin. Humin merupakan fraksi terbesar penyusun senyawa humat dan cara memperolehnya juga relatif mudah (Stevenson,1994). Humin dapat dipandang sebagai suatu polielektrolit makromolekuler yang memiliki gugus utama - $\mathrm{COOH}$ dan gugus - $\mathrm{OH}$ (fenolat) sehingga dapat digunakan sebagai adsorben (Kaled. H, 2011).

Penggunaan metode adsorpsi dalam pengolahan zat warna belum sepenuhnya menyelesaikan permasalahan lingkungan. Adsorben yang telah digunakan untuk proses adsorpsi nantinya akan menimbulkan masalah yang baru sehingga perlu dilakukan desorpsi adsorbat sehingga adsorben dapat digunakan kembali (Peng dkk, 2012). Desorpsi dapat dilakukan dengan mengontakkan adsorben yang telah digunakan dengan larutan yang disebut dengan agen pendesorpsi. Agen pendesorpsi yang digunakan dapat berupa asam, basa, dan netral.

Zat warna indigosol blue yang merupakan senyawa anionik dengan situs aktif $\mathrm{SO}_{3}{ }^{-}$, sehingga dapat diasumsikan bahwa zat warna indigosol blue dapat di desorpsi dengan menggunakan agen pendesorpsi $\mathrm{HCl}$. Larutan asam klorida merupakan asam kuat sehingga anion zat warna indigosol blue akan berinteraksi dengan ion $\mathrm{H}^{+}$dari larutan $\mathrm{HCl}$ dan terlepas dari adsorben humin. Oleh karena itu dalam penelitian ini dibahas mengenai desorpsi zat warna indigosol blue pada adsorben humin. Kajian lain yang dilakukan dalam penelitian ini dengan adanya variasi konsentrasi $\mathrm{HCl}$ pada agen pendesorpsi sehingga dapat mengetahui konsentrasi optimum agen pendesorpsi.

\section{METODE}

\section{Alat dan Bahan}

Alat- alat yang digunakan dalam penelitian ini adalah oven, kertas saring biasa, kertas saring Whatsman 42, labu ukur $100 \mathrm{ml}$, labu ukur $250 \mathrm{ml}$, pipet ukur $1 \mathrm{ml}$, pipet ukur $10 \mathrm{ml}$, neraca analitik, gelas beker $250 \mathrm{ml}$, magnetic stirrer, hot plate, sentrifuge, dan alat-alat analisis : Fourier Transform Infra Red (FT-IR) dan Spektrofotometer UV-Vis.

Bahan-bahan yang digunakan dalam penelitian ini adalah tanah gambut Riau, Sumatera, $\mathrm{HCl} 0,01 ; 0,1 ; 0,5 ; 1,0 ; 1,5$ dan 2,0 M, NaOH $1 \mathrm{M}$, HF 0,3 M, akuades, zat warna Indigosol blue yang biasa digunakan dalam pewarnaan kain dan Natrium Nitrat pa. 


\section{Prosedur}

\section{Penentuan Panjang Gelombang Maksimum dan Kurva Regresi Linear Zat Warna Indigosol Blue}

Larutan induk indigosol blue $250 \mathrm{ppm}$ dibuat dengan menimbang sebanyak 0,025 g indigosol blue, 0,05 g natrium nitrit dan $2 \mathrm{ml} \mathrm{HCl} \mathrm{0,01} \mathrm{M.} \mathrm{Campuran} \mathrm{ketiga} \mathrm{bahan} \mathrm{tersebut}$ kemudian dimasukkan ke dalam labu ukur $250 \mathrm{ml}$ dan diencerkan menggunakan akuades sampai tanda batas. Penentuan panjang gelombang maksimum dengan menggunakan spektrofotometer UV-Vis dengan mengukur besar absorbansi larutan pada panjang gelombang 400-800 nm. Larutan induk kemudian diencerkan pada konsentrasi 5, 10, 15, 20 dan 25 ppm. Kemudian diukur absorbansinya dan dibuat grafik Absorbansi Vs Konsentrasi.

\section{Adsorpsi Humin Terhadap Zat Warna Indigosol Blue}

Adsorpsi berdasarkan kondisi optimum yang diperoleh dari penelitian (Nurhikmah, 2019). Sebanyak $150 \mathrm{mg}$ humin dicampurkan dengan $150 \mathrm{ml}$ larutan zat warna indigosol blue dengan konsentrasi 10 ppm pada pH 5. Campuran dishaker selama 60 menit dengan kecepatan $120 \mathrm{rpm}$ kemudian disaring dengan mengunakan kertas Whatman 42. Filtrat dianalisis dengan menggunakan spektofotometer UV-Vis sesuai dengan bilangan gelombang indigosol blue.

\section{Desorpsi Humin Hasil Adsorpsi}

Sebanyak $25 \mathrm{mg}$ humin hasil adsorpsi dimasukkan kedalam $25 \mathrm{ml}$ akuades dan larutan $\mathrm{HCl}$ dengan variasi konsentrasi 0,$5 ; 1,0 ; 1,5$ dan 2,0 $\mathrm{M}$. Campuran dishaker dengan kecepatan $120 \mathrm{rpm}$ selama 60 menit kemudian disaring dengan menggunakan kertas Whatman 42. Filtrat dianalisis dengan menggunakan spekrofotometer UV-Vis pada bilangan gelombang indigosol blue.

\section{HASIL DAN PEMBAHASAN}

\section{A. Adsorpsi Humin Terhadap Zat Warna Indigosol Blue}

Kondisi pH terlalu asam menyebabkan struktur larutan indigosol blue akan rusak akibat terurainya gugus aktif dari zat warna indigosol blue, hal ini ditandai dengan larutan zat warna tersebut tidak larut dengan sempurna (ada banyak gumpalan berwarna biru). Humin pada kondisi yang terlalu basa akan mengalami deprotonasi sehingga bermuatan pasial negatif sehingga menyebabkan interaksi yang dihasilkan antara indigosol blue dengan humin menjadi lemah. Reaksi yang terjadi disajikan pada persamaan (1) dan (2).

$$
-\mathrm{OH}+\mathrm{H}_{2} \mathrm{O} \longrightarrow-\mathrm{O}^{-}+\mathrm{H}_{3} \mathrm{O}^{+}
$$




$$
-\mathrm{COOH}+\mathrm{H}_{2} \mathrm{O} \longrightarrow \quad-\mathrm{COO}^{-}+\mathrm{H}_{3} \mathrm{O}^{+}
$$

Humin dapat mengadsoprsi dengan maksimum pada $\mathrm{pH}$ 5, karena pada kondisi tersebut gugus fungional $-\mathrm{OH}$ dan $-\mathrm{COOH}$ pada humin akan mengalami protonasi sehingga bermuatan parsial positif. Reaksi yang terjadi disajikan pada persamaan (3) dan (4).

$$
\begin{array}{ccc}
-\mathrm{OH}+\mathrm{H}_{3} \mathrm{O}^{+} & \longrightarrow \mathrm{OH}_{2}^{+}+\mathrm{H}_{2} \mathrm{O} \ldots \ldots \ldots . . . . \\
-\mathrm{COOH}+\mathrm{H}_{3} \mathrm{O}^{+} & \rightarrow-\mathrm{COOH}_{2}^{+}+\mathrm{H}_{2} \mathrm{O} .
\end{array}
$$

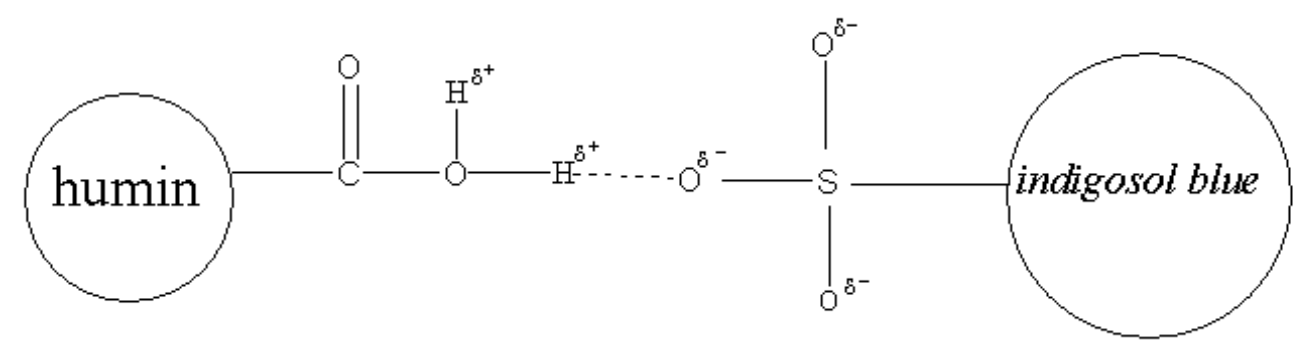

\section{Gambar 2. Ilustrasi reaksi humin dengan zat warna indigosol blue pada saat proses adsorpsi .}

Berdasarkan Gambar 2 dapat diketahui bahwa zat warna indigosol blue merupakan zat warna anionik yang bermuatan parsial negatif, sehingga pada kondisi asam akan mengalami kelebihan $\mathrm{H}^{+}$dan memperkuat interaksi elektrostatik yang menyebabkan terjadinya perpindahan zat warna indigosol blue yang bermuatan parsial negatif menuju ke permukaan humin dengan gugus $-\mathrm{COOH}$ yang bermuatan parsial positif. Atom $\mathrm{H}^{+}$dari humin akan mengikat atom $\mathrm{O}$ dari indigosol blue.

\section{B. Karakterisai Humin Sebelum Adsorpsi, Setelah Adsorpsi dan Setelah Desorpsi}

Karakterisasi adsorben humin dilakukan untuk menganalisisperbedaan serapan gugus fungsional yang ada dalam adsorben setelah adsorpsi dan desorpsi. Interpretasi spektra FT-IR pada gugus fungsional humin sebelum adsorpsi, setelah adsorpsi dan setelah proses desorpsi tersaji pada Gambar 3.

Setelah proses adsorpsi, terjadi pergeseran bilangan gelombang dari bilangan gelombang 3425,58 $\mathrm{cm}^{-1}$ bergeser ke bilangan gelombang $3410,15 \mathrm{~cm}^{-1}$ dan semakin berkurangnya intensitas pada puncak serapan tersebut menunjukkan bahwa situs aktif $-\mathrm{OH}$ yang semakin berkurang dikarenakan situs aktif $-\mathrm{OH}$ yang terprotonasi membentuk $-\mathrm{OH}_{2}^{+}$ berinteraksi dengan anion zat warna indigosol blue. Adanya pergeseran bilangan gelombang 
$1627,92 \mathrm{~cm}^{-1}$ menjadi $1620,21 \mathrm{~cm}^{-1}$ dan intensitas pada puncak yang semakin berkurang setelah dilakukan proses adsorpsi. Semakin berkurangnya intensitas pada puncak tersebut menunjukkan adanya interaksi antara adsorben humin dengan zat warna indigosol blue.

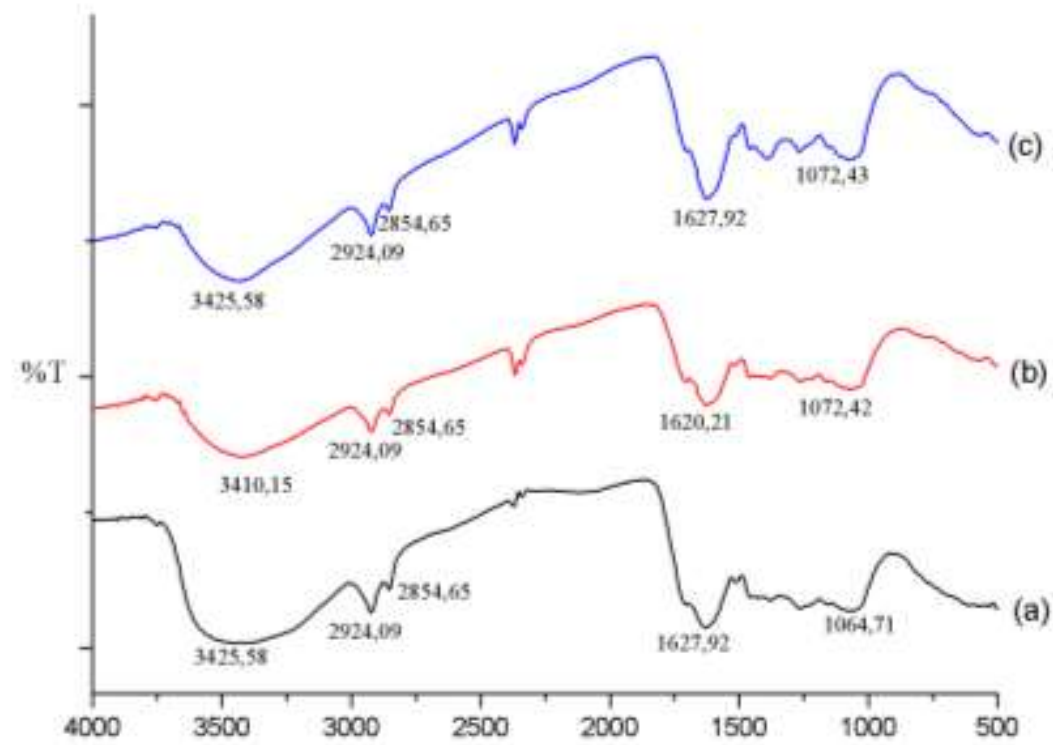

Gambar 3. Hasil Spektra FTIR Gugus Fungsional Humin (a) Sebelum Adsorpsi, (b) Setelah Adsorpsi, dan (c) Setelah Desorpsi

Interpretasi spektra FT-IR setelah desorpsi yang disajikan pada Gambar 4 menunjukkan serapan dengan intensitas puncak yang bertambah pada bilangan gelombang 1705,07 $\mathrm{m}^{-1}$ menunjukkan adanya vibrasi ulur $-\mathrm{C}=\mathrm{O}$ dari $-\mathrm{COOH}$. Penggunaan $\mathrm{HCl}$ dalam proses desorpsi menyebabkan zat warna indigosol blue pada adsorben humin akan berinteraksi dengan ion $\mathrm{H}^{+}$yang berasal dari larutan $\mathrm{HCl}$ dan akan melarutkan pengotor yang masih ada dalam adsorben humin sehingga gugus fungsional - $\mathrm{COOH}$ semakin tampak serapannya didalam spektra FT-IR. Pergeseran bilangan gelombang dari 1620,21 $\mathrm{cm}^{-1}$ menjadi 1627,92 $\mathrm{cm}^{-1}$ menunjukkan bahwa anion zat warna indigosol blue telah terdesorp sehingga bilangan gelombang kembali seperti humin setelah dimurnikan.

\section{Desorpsi Humin Hasil Adsorpsi}

Parameter yang digunakan untuk mengkaji desorpsi zat warna indigosol blue dengan adsorben humin adalah menggunakan variasi konsentrasi dengan mempelajari jumlah pelepasan zat warna indigosol blue menggunakan agen pendesorpsi $\mathrm{HCl}$ pada variasi konsentrasi 0,$5 ; 1,0 ; 1,5 ; 2,0 \mathrm{M}$ dan tanpa menggunakan agen pendesorpsi. Penggunaan asam klorida $(\mathrm{HCl})$ bertujuan untuk me-recovery humin dan juga untuk memisahkan zat warna 
indigosol blue yang telah diadsorpsi oleh adsorben humin. Hasil desorpsi penelitian ini disajikan pada Tabel 1 .

Tabel 1. Persen desorpsi zat warna indigosol blue pada adsorben humin

\begin{tabular}{cc}
\hline Konsentrasi HCL (M) & Persen Desorpsi (\%) \\
\hline 0 & 20,32 \\
0,5 & 62,26 \\
1,0 & 68,71 \\
1,5 & 81,61 \\
2,0 & 17,10 \\
\hline
\end{tabular}

Berdasarkan Tabel 1 dapat diketahui bahwa jumlah anion yang terdesorpsi tanpa agen pendesorpsi sebanyak 20,32\%. Adanya ion $\mathrm{H}^{+}$dalam medium $\mathrm{H}_{2} \mathrm{O}$ menyebabkan anion dari zat warna indigosol blue berinteraksi dengan akuades. Sedikitnya jumlah anion yang terdesorpsi ini dikarenakan ion $\mathrm{H}^{+}$yang terdapat dalam akuades tidak cukup kuat untuk mendesorpsi zat warna indigosol blue.

Desorpsi dengan variasi konsentrasi 0,5 $\mathrm{M}$ dan $1 \mathrm{M}$ menghasilkan persen desorpsi sebanyak 62,26\% dan 68,71\%, lebih sedikit dibandingkan dengan konsentrasi 1,5 M yang menghasilkan persen desorpsi sebanyak 81,61\%. Semakin tinggi konsentrasi agen pendesorpsi $(\mathrm{HCl})$ akan meningkatkan jumlah ion $\mathrm{H}^{+}$sehingga zat warna indigosol blue yang terdesorpsi juga akan semakin meningkat. Keberadaan larutan $\mathrm{HCl}$ dalam desorpsi ini sangat mempengaruhi proses desorpsi zat warna indigosol blue karena kekuatan ion $\mathrm{H}^{+}$dari $\mathrm{HCl}$ akan melepaskan anion zat warna indigosol blue yang telah berinteraksi dengan adsorben humin.

Hasil analisis desorpsi indigosol blue yang diperoleh dapat diketahui bahwa kekuatan ion $\mathrm{H}^{+}$dari $\mathrm{HCl}$ dapat mendesorpsi zat warna indigosol blue yang telah berinteraksi dengan adsorben humin. Keberadaan larutan $\mathrm{HCl}$ sangat mempengaruhi desorpsi zat warna indigosol blue karena asam klorida yang merupakan asam kuat dapat terprotonasi dan melepaskan ion $\mathrm{H}^{+}$. Protonasi asam klorida $(\mathrm{HCl})$ menyebabkan zat warna indigosol blue lebih suka berinteraksi dengan ion $\mathrm{H}^{+}$dari $\mathrm{HCl}$ dari pada adsoben humin karena memiliki interaksi elektrostatik yang lebih besar dibandingkan dengan adsorben humin sehingga dapat mengikat zat warna indigosol blue. 
Mekanisme terjadinya desorpsi zat warna indigosol blue dari adsorben humin dapat diketahui berdasarkan Gambar 4.

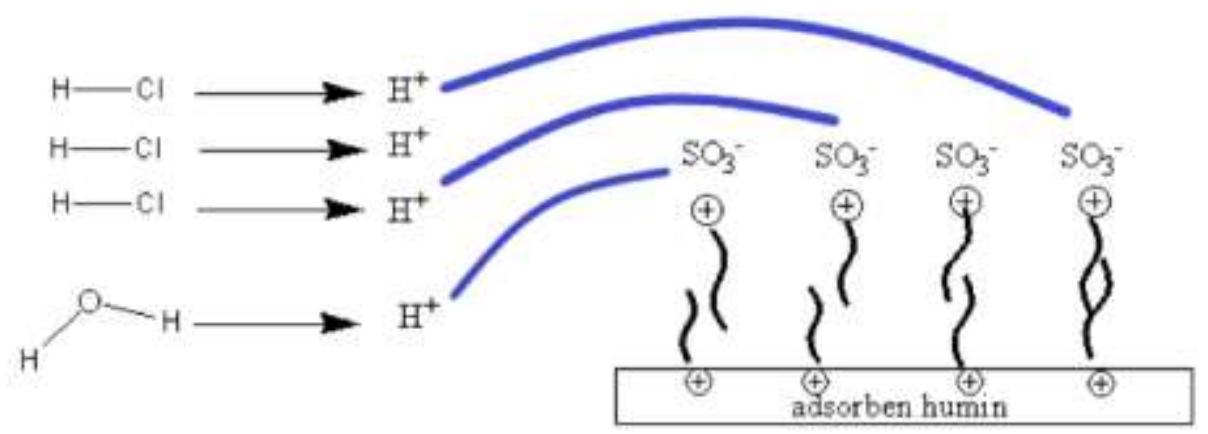

Gambar 4. Indigosol blue yang terdesorpsi dari adsorben humin lewat pertukaran ion

\section{KESIMPULAN}

Setelah proses adsorpsi, terjadi pergeseran bilangan gelombang pada serapan gugusgugus fungsional humin yang menunjukkan bahwa adanya zat warna indigosol blue yang berikatan dengan adsorben humin. Setelah proses desorpsi, terjadi pergeseran bilangan gelombang beberapa serapan gugus-gugus fungsional humin yang menunjukkan bahwa zat warna indigosol blue berhasil terdesorpsi dari adsorben humin.

Persen desorpsi zat warna indigosol blue semakin meningkat seiring dengan bertambahnya konsentrasi agen pendesorpsi. Hasil yang diperoleh menunjukkan bahwa konsentrasi maksimum agen pendesorpsi adalah 1,5 $\mathrm{M}$ dengan persen desorpsi sebesar $81,61 \%$.

\section{DAFTAR PUSTAKA}

Atkins. P. W., 1999. Kimia Fisika. (diterjemahkan oleh : Kartahadiprojo Irma I) edisi ke-2. Jakarta: Erlangga

Heland., Shina Indah. 2018. The Adsorption and Regeneration of Natural Pumice as Low Cost Adsorbent for Nitrate Removal From Water. Faculty of Engineering. Universitas Andalas

Kaled .H., dan and Fawy H., A., 2011. Effect of different levels of humic acids on the nutrient content, plant growth, and soil properties under condititions of sanity, soil \& water res., $6,(1): 21-29$

Larasati. 2018. Adsorpsi Zat Warna Naftol Menggunakan Adsorben Humin Hasil Isolasi Tanah Gambut Sumatera. Fakultas Saintek UIN Sunan Kalijga: Yogyakarta

Nurhikmah. 2019. Adsorpi Zat Warna Indisgosol Blue pada Humin Hasil Isolasi Tanah Gambut Sumatera. Fakulta Saintek UIN Sunan Kalijga: Yogyakarta 
Peng dkk. 2011. Modifying $\mathrm{Fe}_{3} \mathrm{O}_{4}$ nanoparticles with humic acid for removal Rhodamin $\mathrm{B}$ in water. Epartement of Enviromental Science and Engineering Human Agricultur University. China

Suparno, 2010. Degredai Zat Warna Indigosol dengan Metode Oksidasi Katalitik Menggunakan Zeolit Alam Teraktivasi dan Ozonasi. Tesis :Program Pascasarjana Kimia Universitas Indonesia, Depok.

Stevenson, F. J., 1994 Humus Chemistry. Genesis, Composition, Reactions, John Wiley and Sons, New York

Wang., Liming Li., Xuegang Zou., Ranjun Shu., Ling Ding., Kun Yao., Wenying Lv \& Guoguang Liu. 2016. Impact of Humin an Soil Adsorption and Remidiation of Cd(II), $\mathrm{Pb}(\mathrm{II})$, and $\mathrm{Cu}(\mathrm{II})$. School of Enviromental Science and Engineering. Guangdong University of Technology; China. 